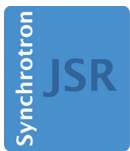

JOURNAL OF

SYNCHROTRON

RADIATION

ISSN 1600-5775

Received 23 March 2016

Accepted 15 October 2016

Edited by I. Schlichting, Max Planck Institute for Medical Research, Germany

₹ Present address: Department of Agricultural, Food and Environmental Sciences, Università Politecnica delle Marche, Via Brecce Bianche, 60131 Ancona, Italy.

Keywords: phasing; sulfur SAD; variable beam; low-energy data collection; $2 \theta$-detector arm; softer X-rays; tunability.

Supporting information: this article has supporting information at journals.iucr.org/s

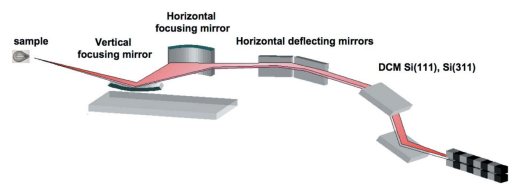

OPEN $\odot$ ACCESS

\section{P13, the EMBL macromolecular crystallography beamline at the low-emittance PETRA III ring for high- and low-energy phasing with variable beam focusing}

\author{
Michele Cianci, ${ }^{\mathrm{a}}$ G Gleb Bourenkov, ${ }^{\mathrm{a}}$ Guillaume Pompidor, ${ }^{\mathrm{a}}$ Ivars Karpics, ${ }^{\mathrm{a}}$ \\ Johanna Kallio, ${ }^{\mathrm{a}}$ Isabel Bento, ${ }^{\mathrm{a}}$ Manfred Roessle, ${ }^{\mathrm{a}, \mathrm{b}}$ Florent Cipriani, ${ }^{\mathrm{c}}$ \\ Stefan Fiedler ${ }^{\mathrm{a} *}$ and Thomas R. Schneider ${ }^{\mathrm{a} *}$ \\ ${ }^{\mathbf{a}}$ Hamburg Unit c/o DESY, European Molecular Biology Laboratory (EMBL), Notkestrasse 85, 22603 Hamburg, \\ Germany, ${ }^{\mathbf{b}}$ Fachhochschule Lübeck, Fachbereich Angewandte Naturwissenschaften, Mönkhofer Weg 239, \\ 23562 Lübeck, Germany, and ${ }^{\mathbf{C}}$ European Molecular Biology Laboratory, Institut Laue-Langevin, BP 181, \\ 6 rue Jules Horowitz, 38042 Grenoble Cedex 9, France. *Correspondence e-mail: fiedler@embl-hamburg.de, \\ thomas.schneider@embl-hamburg.de
}

The macromolecular crystallography P13 beamline is part of the European Molecular Biology Laboratory Integrated Facility for Structural Biology at PETRA III (DESY, Hamburg, Germany) and has been in user operation since mid-2013. P13 is tunable across the energy range from 4 to $17.5 \mathrm{keV}$ to support crystallographic data acquisition exploiting a wide range of elemental absorption edges for experimental phase determination. An adaptive Kirkpatrick-Baez focusing system provides an X-ray beam with a high photon flux and tunable focus size to adapt to diverse experimental situations. Data collections at energies as low as $4 \mathrm{keV}(\lambda=3.1 \AA)$ are possible due to a beamline design minimizing background and maximizing photon flux particularly at low energy (up to $10^{11}$ photons $\mathrm{s}^{-1}$ at $4 \mathrm{keV}$ ), a custom calibration of the PILATUS $6 \mathrm{M}-\mathrm{F}$ detector for use at low energies, and the availability of a helium path. At high energies, the high photon flux $\left(5.4 \times 10^{11}\right.$ photons s $^{-1}$ at $\left.17.5 \mathrm{keV}\right)$ combined with a large area detector mounted on a $2 \theta$ arm allows data collection to sub-atomic resolution $(0.55 \AA)$. A peak flux of about $8.0 \times 10^{12}$ photons s$^{-1}$ is reached at $11 \mathrm{keV}$. Automated sample mounting is available by means of the robotic sample changer 'MARVIN' with a dewar capacity of 160 samples. In close proximity to the beamline, laboratories have been set up for sample preparation and characterization; a laboratory specifically equipped for on-site heavy atom derivatization with a library of more than 150 compounds is available to beamline users.

\section{Introduction}

In 2009, DESY completed the conversion of the $2.3 \mathrm{~km}$-long PETRA ring, previously used as an injector for high-energy physics experiments on HERA, into a dedicated synchrotron radiation source with an emittance of $1.1 \mathrm{~nm}$ rad (Balewski et al., 2004). On PETRA III, three beamlines for structural biology have been designed and constructed by EMBL Hamburg: P12 for small-angle X-ray scattering on solutions of biological macromolecules (SAXS) in sector 8, and P13 and P14 for macromolecular crystallography (MX) in sector 9. The beamlines are embedded in the 'EMBL Integrated Facility for Structural Biology' that provides instruments and support for the characterization, preparation and crystallization of samples (Boivin et al., 2016) for subsequent use in SAXS and/ or MX experiments. 
(a)
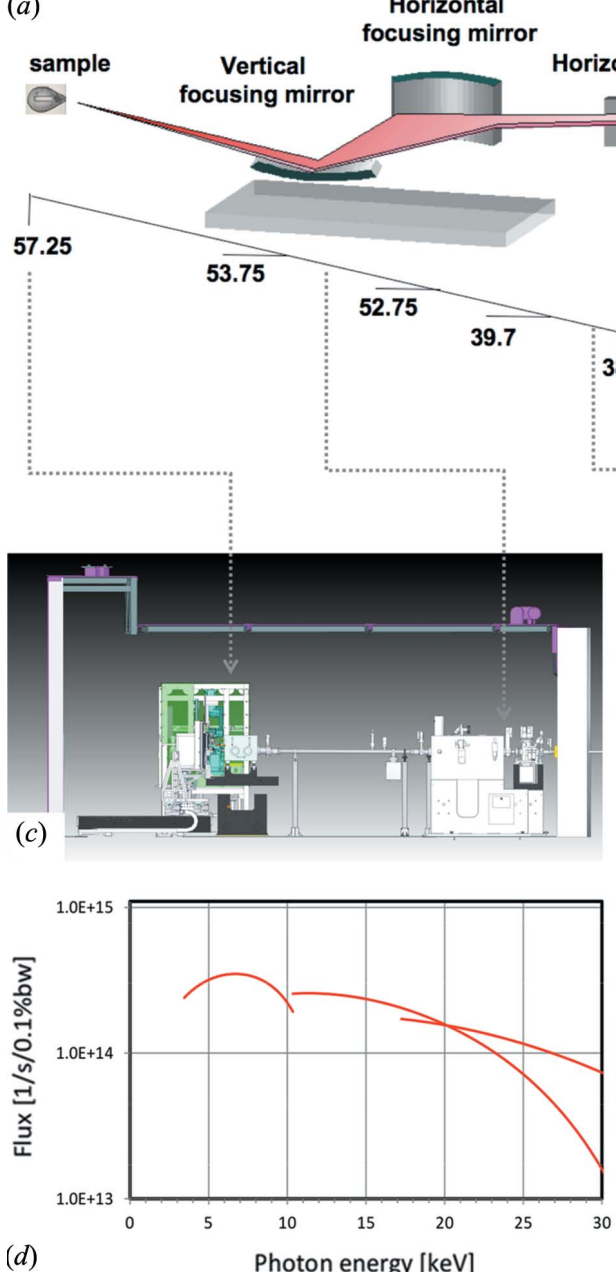

(d)

Photon energy $[\mathrm{keV}]$
Horizontal deflecting mirrors

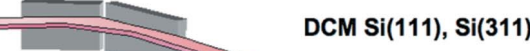

(b)

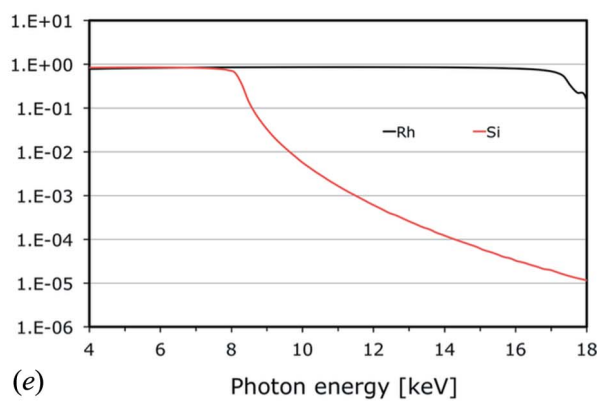

Figure 1

P13 beamline. (a) Optical layout; assembly drawing of (b) the optics hutch, (c) the experimental hutch, (d) predicted flux of the $2 \mathrm{~m} \mathrm{U} 29$ undulator through a $1 \mathrm{~mm} \times 1 \mathrm{~mm}$ aperture at $40 \mathrm{~m}$ distance from the source at the PETRA III storage ring (DESY, Hamburg), (e) reflectivity of photon beam versus energy through the double horizontal deflecting mirror for Rh coating (black line) and uncoated silica (red line).

P13 was designed to exploit the unique properties of PETRA III in terms of low emittance and high energy for addressing challenging crystal structure determinations. For phasing applications, tunability across a wide range of energies (4-17.5 keV) was implemented to exploit many different elemental absorption edges for MAD (multi-wavelength anomalous diffraction) or SAD (single-wavelength anomalous diffraction) phasing. An optical configuration with a beam demagnification of $1: 12$ horizontally and $1: 15$ vertically was chosen to maintain a small beam divergence while achieving a 20-30 $\mu \mathrm{m}$ spot size to be able to extract high-quality diffraction data from small crystals with large unit cells. To provide optimum conditions for different types of crystals, adaptive X-ray mirrors, exchangeable apertures and finely adjustable beam absorbers have been installed to tailor the beam properties rapidly to match the properties of a crystal mounted on the diffractometer. In the design and during the commissioning of the beamline, particular attention was paid to enabling data collections at energies lower than $6 \mathrm{keV}$ to enhance the anomalous signal measurable from sulfur and/or phosphorus atoms while maintaining high photon fluxes into small beam cross sections. Data collection at energies above $6 \mathrm{keV}$ is performed in air, while for energies between 4 and $6 \mathrm{keV}$ a helium cone is used to reduce air-scatter. Other beamlines capable of reaching low energies have chosen other approaches. While the I23 beamline at Diamond (UK) (Wagner et al., 2016) features a complete in vacuum setup and a wavelength range from 1.5 to $4 \AA(8-3 \mathrm{keV})$, the BL-1A beamline at the Photon Factory (Tsukuba, Japan) (Liebschner et al., 2016) offers a full in helium setup with limited tunability extending over the wavelength ranges $0.95-1.1 \AA \quad(12.5-$ $11.5 \mathrm{keV})$ and $2.7-3.3 \AA$ (4.6$3.7 \mathrm{keV})$.

The co-location of beamlines P13 and P14 on a pair of canted undulators in a relative short and narrow sector of the PETRA III synchrotron posed a number of technical challenges that needed to be addressed in design and construction. The design of beamline P13 began in 2007, with general user operation commencing in 2013 (for a more detailed timeline see Table S1 of the supporting information). The overall layout of the beamline is shown in Figs. 1(a)-1(c); details can be found in Table 1 .

\section{Beamline overview}

\subsection{Storage ring and insertion device}

PETRA III is a storage ring with a circumference of $2304 \mathrm{~m}$ operated at an energy of $6.084 \mathrm{GeV}$ with a horizontal emittance of $1.1 \mathrm{~nm}$ rad (Franz et al., 2007). The ring current is injected in top-up mode with various bunch-filling patterns $(40,60,240,480,960$ bunch modes) up to a current of $100 \mathrm{~mA}$ in normal operation. In the $5 \mathrm{~m}$-long high- $\beta$ straight section of sector 9 of the PETRA III ring a pair of undulators with a canting angle of $5 \mathrm{mrad}$ produces two independent X-ray beams for the P13 and P14 beamlines. The U29-2 2 m-long undulator (Barthelmess et al., 2008) deployed in $\mathrm{P} 13$ produces an X-ray beam with dimensions (RMS) of $140 \mu \mathrm{m}(\mathrm{H}) \times$ $5.6 \mu \mathrm{m}(\mathrm{V})$ and divergence (RMS) of $7.9 \mu \mathrm{rad}(\mathrm{H}) \times 4.2 \mu \mathrm{rad}$ (V) at $10 \mathrm{keV}$ (Balewski et al., 2004; Franz et al., 2007). 
Table 1

PETRA III and EMBL P13 beamline details.

\begin{tabular}{|c|c|}
\hline Storage ring & PETRA III, DESY, Germany \\
\hline Circumference & $2304 \mathrm{~m}$ \\
\hline Particle energy & $6 \mathrm{GeV}$ \\
\hline Particle current (planned) & $100(200) \mathrm{mA}$ \\
\hline Horizontal emittance & $1 \mathrm{~nm} \mathrm{rad}$ \\
\hline Beamline name & P13 \\
\hline Source type & $\mathrm{U} 29-2,2 \mathrm{~m}$ \\
\hline Monochromator $(36.8) \dagger$ & $\begin{array}{l}\text { Oxford-FMB, UK; } \mathrm{Si}(111) \text { or } \\
\text { Si(311); both crystals LN2 } \\
\text { cooled, fixed exit }\end{array}$ \\
\hline First deflecting mirror $(38.7) \dagger$ & $\begin{array}{l}3.8 \text { mrad, silica substrate }+ \text { Rh } \\
\text { coating, } 400 \mathrm{~mm} \text { optical surface } \\
\text { length }[0.32 \mu \mathrm{rad}]\end{array}$ \\
\hline Second deflecting mirror $(39.7) \dagger$ & $\begin{array}{l}3.8 \text { mrad, silica substrate }+\mathrm{Rh} \\
\text { coating, } 400 \mathrm{~mm} \text { optical surface } \\
\text { length }[0.29 \mu \mathrm{rad}]\end{array}$ \\
\hline Horizontal focusing mirror $(52.75) \dagger$ & $\begin{array}{l}3.8 \text { mrad, silica substrate }+ \text { Rh } \\
\text { coating, } 400 \mathrm{~mm} \text { optical surface } \\
\text { length }[0.39 \mu \mathrm{rad} \text { with adaptive } \\
\text { mirror corrections }]\end{array}$ \\
\hline Vertical focusing mirror $(53.75) \dagger$ & $\begin{array}{l}3.8 \text { mrad, silica substrate }+\mathrm{Rh} \\
\text { coating, } 250 \mathrm{~mm} \text { optical surface } \\
\text { length }[0.44 \mu \mathrm{rad} \text { with adaptive } \\
\text { mirror corrections] }\end{array}$ \\
\hline Energy range $(\mathrm{keV})$ & $4-17.5$ \\
\hline Wavelength range $(\AA)$ & $3.1-0.7$ \\
\hline $\begin{array}{l}\text { Beam size [focused, defocused, } \\
\mathrm{H} \times \mathrm{V}(\mu \mathrm{m})] \text { FWHM }(57.25) \dagger\end{array}$ & $30 \times 24,150 \times 70$ \\
\hline $\begin{array}{l}\text { Beam diameter (collimated, typical) } \\
(\mu \mathrm{m})\end{array}$ & $5,10,15,30,50,70,100$ \\
\hline Beam divergence $(\mathrm{H} \times \mathrm{V})(\mathrm{mrad})$ & $0.23 \times 0.15$ \\
\hline Goniometer & $\begin{array}{l}\text { ARINAX MD2, horizontal single } \\
\text { axis, with mini- } \kappa \text { goniometer } \\
\text { option }\end{array}$ \\
\hline Cryo capability & $\begin{array}{l}\text { Cryostream } 800 \text { series (Oxford } \\
\text { CryoSystems, Oxford, UK) }\end{array}$ \\
\hline Sample mounting & $\begin{array}{l}\text { Manual/MARVIN Sample } \\
\text { Changer, capacity of } 16+1 \\
\text { EMBL/ESRF pucks with SPINE } \\
\text { standard pins and vials }\end{array}$ \\
\hline Detector model & $\begin{array}{l}\text { DECTRIS PILATUS 6M-F with } \\
\text { custom calibration table for } \\
\text { energies } 4-20 \mathrm{keV}\end{array}$ \\
\hline $2 \theta$ capabilities & Yes, vertical $25^{\circ}$ \\
\hline
\end{tabular}

$\dagger$ Distance in meters from the source.

The energy ranges for the different harmonics are shown in Fig. 1(d).

\subsection{Monochromator}

A customized version of the high-heat-load FMBOXFORD (Oxford, UK) double-crystal monochromator (DCM) has been installed as the first optical element at $36.8 \mathrm{~m}$ distance from the source (Fig. 1a). The DCM contains two interchangeable pairs of crystals: while the Si(111) crystals are used for standard applications over the entire energy range with $\Delta E / E<2 \times 10^{-4}$, the $\operatorname{Si}(311)$ crystals can be used for applications requiring high-energy resolution $(\Delta E / E<5 \times$ $10^{-5}$ ) over a limited energy range $(6-17 \mathrm{keV})$. The monochromator is indirectly cooled by a closed-loop liquid-nitrogen (LN2) cryostat. The first crystal is clamped between sidecooling blocks through which the cryogen is flowing. The cooling blocks of the second crystal are coupled by copper braids to the cooling blocks of the first crystal. After initial exposure of the cold monochromator to the full white beam, thermal equilibrium of the second crystal with temperature fluctuations of less than $0.1^{\circ} \mathrm{C}$ is reached in about $45 \mathrm{~min}$. The vibrational stability of the double-crystal set has been iteratively improved to currently better than 85 nrad r.m.s. during static operation.

\subsection{Horizontal deflecting mirrors}

Following the design used at GM/CA-CAT at the Advanced Photon Source (Fischetti et al., 2005, 2007), we introduced two horizontally deflecting mirrors (HDMs) at $38.7 \mathrm{~m}$ and $39.7 \mathrm{~m}$ from the source, respectively, each providing a fixed $3.8 \mathrm{mrad}$ incident angle resulting in a total horizontal deflection of the beam of $15.2 \mathrm{mrad}$ (Figs. 1a, 1b), with a corresponding horizontal separation between the two beams at the P13 sample position of $548 \mathrm{~mm}$ (Fig. 3). Specifications of the two mirrors, manufactured by SESO (Aix-en-Provence, France), are reported in Table 1. Bruker ASC (Bergisch-Gladbach, Germany) supplied the HDM mirror assembly. High-resolution slope error measurements of the mirror surfaces were carried out at the Helmholtz-Zentrum-Berlin (BESSY-II, Institut für Nanometer Optik und Technologie) with the nanometer optical component measuring machine (NOM), according to the protocol reported by Siewert et al. (2012) for the characterization of the P13 KB mirrors. A Rh-coated region is used for operation in the energy range $6-17.5 \mathrm{keV}$. The uncoated silica region is used at energies below $6 \mathrm{keV}$ and facilitates the suppression of high-energy harmonics (Fig. 1e). The reflectivity of each mirror is above $70 \%$ between $4 \mathrm{keV}$ and $17 \mathrm{keV}$. For energies above $17 \mathrm{keV}$, the reflectivity drops sharply to less than $20 \%$.

\subsection{Focusing mirrors}

A pair of multi-segmented piezo-electrically adaptable mirrors (Signorato et al., 1998), manufactured by SESO (Aixen-Provence, France), commonly referred to as bimorph mirrors, in Kirkpatrick-Baez (KB) configuration, is deployed for focusing. Bruker ASC (Bergisch-Gladbach, Germany) supplied the KB mirror assembly. Specifications are reported in Table 1. The KB mirrors generate a minimum focus of $30 \mu \mathrm{m}(\mathrm{H}) \times 24 \mu \mathrm{m}(\mathrm{V})(\mathrm{FWHM})$ at the sample position. $\mathrm{X}$-ray intensities for different energies and beam sizes under different focusing/collimating conditions are reported in Fig. 2(a) and in Table S2 of the supporting information. The bimorph mirrors enable the defocusing of the beam both in the horizontal and/or the vertical direction on a timescale of minutes (Fig. $2 b$ ) up to a beam size of $150 \mu \mathrm{m}(\mathrm{H})$ and $70 \mu \mathrm{m}$ (V), without significant loss of photon flux (see the video recording in real time of vertical defocusing in the supporting information). The estimated beam divergence for the $30 \mu \mathrm{m}$ $(\mathrm{H}) \times 24 \mu \mathrm{m}(\mathrm{V})(\mathrm{FWHM})$ beam focused at the sample position is predicted to be $230 \mu \mathrm{rad}(\mathrm{H}) \times 150 \mu \mathrm{rad}(\mathrm{V})$ (FWHM) (equivalent to $\sim 0.01^{\circ}$ ), decreasing to $190 \mu \mathrm{rad}(\mathrm{H})$ $\times 110 \mu \mathrm{rad}(\mathrm{V})$ when the beam is focused at $1 \mathrm{~m}$ downstream of the sample position (Fig. S2). The beam profile is close to 


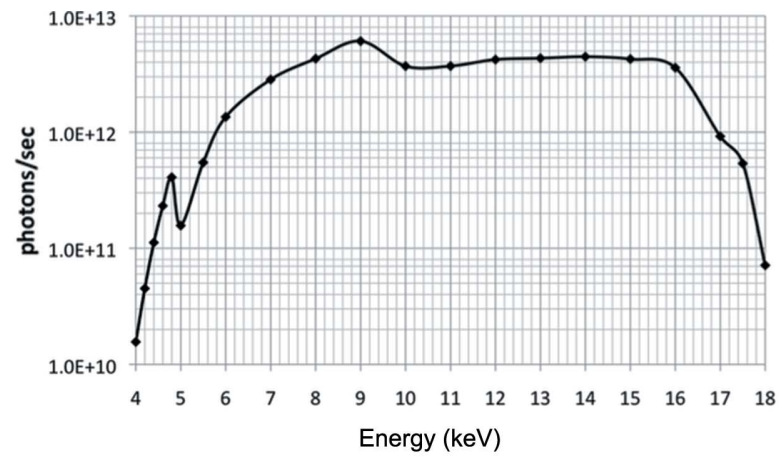

(a)

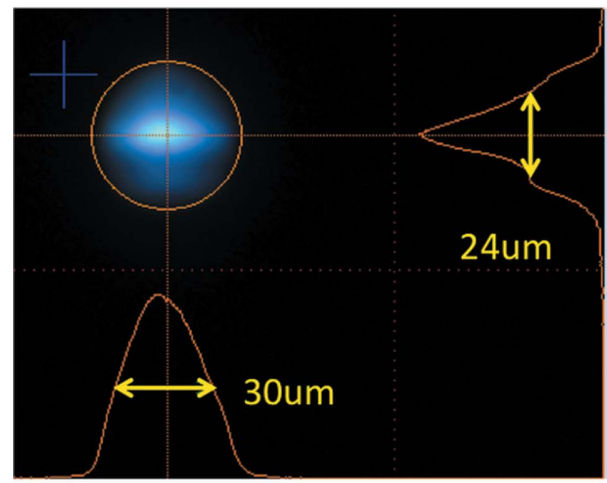

(c)

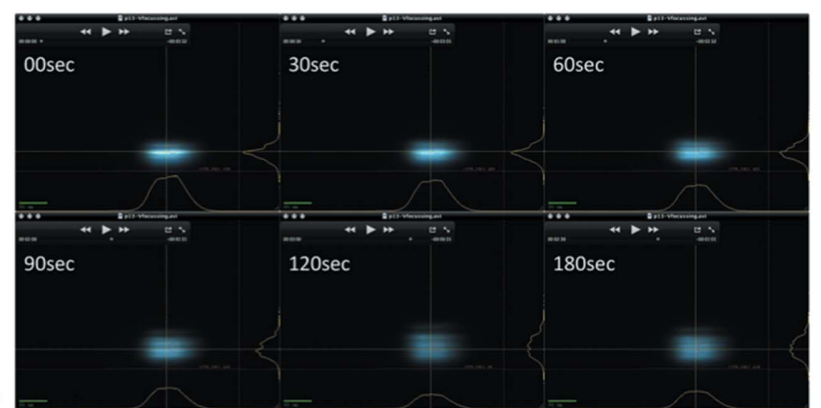

(b)

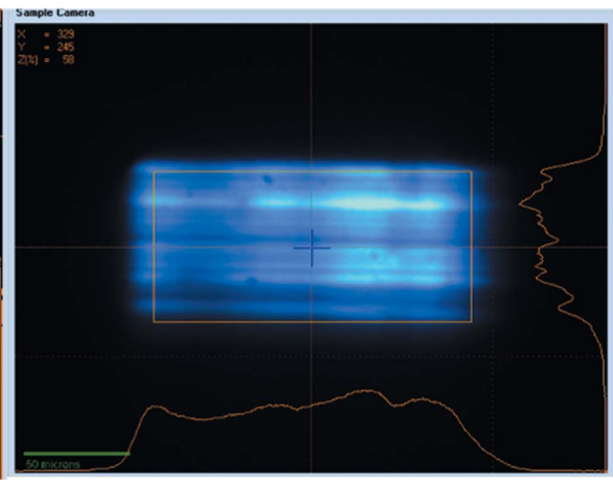

$(d)$

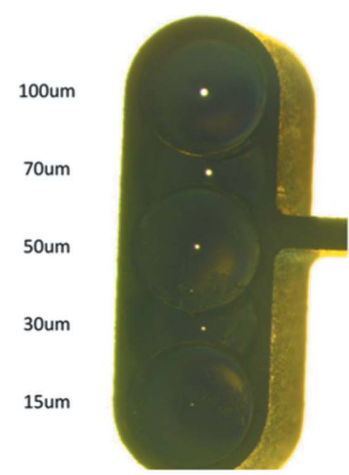

(e)

Figure 2

Beam size and photon flux. (a) Total photon flux as a function of energy at the sample position for fully focused beam; $(b)$ time course of beam profile during the vertical defocusing procedure from $24 \mu \mathrm{m}$ to $70 \mu \mathrm{m}$ over a period of $180 \mathrm{~s} ;(c)$ beam profile of the fully focused beam $30 \mu \mathrm{m}(\mathrm{H}) \times 24 \mu \mathrm{m}(\mathrm{V})$ at the sample position, determined with the built-in scintillator of MD2; $(d)$ defocused beam of $150 \mu \mathrm{m}(\mathrm{H}) \times 70 \mu \mathrm{m}(\mathrm{V})$ size; $(e)$ MD2 penta-aperture with aperture sizes indicated.

Gaussian when focused (Fig. 2c), while when defocused it shows a characteristic structure with horizontal striations (Fig. $2 d$ ), as predicted by X-ray tracing (Fig. S2), due to the mismatch between the small vertical beam emittance and the slope errors of the vertical focusing mirror remaining after adaptive optimization. Here, it should be noted that the striated beam profile does not impede the collection of highquality diffraction data.

\subsection{Slit systems}

The shape and size of the white beam is defined by a set of water-cooled white-beam slits in the front-end as provided by DESY (Schulte-Schrepping et al., 2013). Secondary slits at the height of the fixed-exit monochromator suppress the background scatter produced in the DCM and are adjusted to the acceptance of the first of the deflecting mirrors. Two pairs of slits (CINEL, Vigonza, Italy) with a positional reproducibility of $1 \mu \mathrm{m}$, one after the HDM and one before the KB system, serve as collimators and define the effectively used surface of the KB mirrors.

\subsection{Beam monitors}

A permanent fluorescence beam imaging and intensitymonitoring device, harnessing the light emitted from the CVD diamond window (DESY-EMBL development), has been installed immediately upstream of the DCM for alignment of the front-end aperture and white-beam slits.

Removable fluorescence beam imaging screens are deployed after: (a) the DCM for its alignment as well as for the source position/shape characterization and diagnostics using the monochromatic beam; $(b)$ the HDM pair as a first control of beam deflection; $(c)$ the KB system, where knowledge of the beam position is required for alignment of the KB system with respect to the optical axis.

Beam intensity and position monitors are installed at each slit system and after the KB mirrors, and, together with a piezo actuator driven feedback, are used for detecting drifts. Two intensity monitors in the beam-conditioning unit (see below) can be used for precise exposure dose determination.

\subsection{Diamond windows}

There are currently two CVD diamond windows $(60 \mu \mathrm{m}$ thickness, $5 \mathrm{~mm}$ diameter; Diamond Materials $\mathrm{GmbH}$, Freiburg, Germany) installed in the beamline. The first one ( $36.5 \mathrm{~m}$ from the source) is used to separate the front-end vacuum section from the beamline optics, while the second one $(56.25 \mathrm{~m}$ from the source) separates the vacuum of the beam-conditioning unit from the rest of beamline optics.

\subsection{Experimental table}

The five-degrees-of-freedom granite experimental table [1.2 $\mathrm{m}$ (length, $\mathrm{L}) \times 1.0 \mathrm{~m}($ width, $\mathrm{W})]$, an in-house design and 
production, supports the beam-conditioning unit, the MD2 and the fluorescence detector.

The beam-conditioning unit (BCU) is an in-house development of a self-contained in-vacuum unit to collimate, attenuate, characterize and monitor the photon beam. It has a modular design and can be adapted to tight geometrical restrictions. The vessel (Fig. 3) has a size of $510 \mathrm{~mm}$ (L) $\times$ $350 \mathrm{~mm}(\mathrm{~W}) \times 385 \mathrm{~mm}(\mathrm{H})$ and houses two fine slits (horizontal and vertical), based on translations by attocube systems AG (München, Germany) with nanometer resolution, a fast shutter module (CEDRAT Technologies, Meylan, France), an attenuator module with an option for 1000 filter combinations and two monitoring modules with a beam intensity monitoring and beam viewing options. The two sets of slits in the BCU (see below) define the optical axis of the experimental table. When a defocused beam is used, the last set of slits serves as a variable beam-defining aperture $(30-200 \mu \mathrm{m})$ with submicrometer precision.

An MD2 diffractometer (Cipriani et al., 2007) with a mini- $\kappa$ goniometer head MK3 (ARINAX, Moirans, France) (Figs. 3 and S5) is installed as the diffractometer. The measured $\omega$-axis sphere-of-confusion (SOC) is $0.9 \mu \mathrm{m}$ peak-to-peak diameter without the MK3 installed. With the MK3 installed, the SOC is $2.4 \mu \mathrm{m}$ at $\kappa=0^{\circ}$ with a slight increase $(<0.1 \mu \mathrm{m})$ for $\kappa=60^{\circ}$ (Fig. S4). The continuous shutterless helical (four-dimensional) scanning capability (Flot et al., 2010; de Sanctis et al., 2012) is fully implemented.

A set of fixed-diameter circular apertures at $30 \mathrm{~mm}$ distance from the sample position are used either as scatter trap, cleaning or beam-defining aperture depending on the focusing/defocusing conditions. The standard set is a five-hole beam-defining aperture such that the X-ray beam can be shaped to $15,30,50,70$ or $100 \mu \mathrm{m}$-diameter sizes (Fig. 2e); the second set that can be optionally mounted features 50,10 and $5 \mu \mathrm{m}$-diameter apertures and is used to provide mini-beam conditions (Fischetti et al., 2009). A further scatter trap aperture at $8 \mathrm{~mm}$ from the sample position is part of a capillary-backstop assembly (Fig. S5).

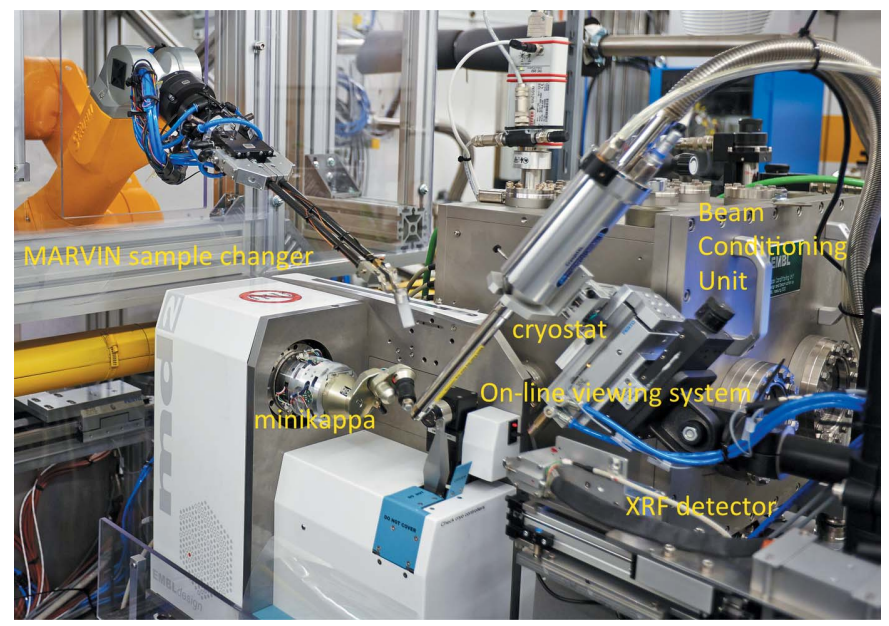

Figure 3

P13 sample environment around the MD2 goniometer with the MARVIN sample changer on the left and the BCU at the back.
A retractable Amptek XR-100SDD fluorescence detector (Amptek, Inc., Bedford, MA, USA) is installed for X-ray absorption-edge scans for MAD experiments and for elemental analysis (Fig. 3).

\subsection{Sample changer and cryogenics}

A MARVIN sample changer system (EMBL Hamburg inhouse design) is available on P13 (Fig. 3), with a storage dewar capacity of $16 \mathrm{EMBL} / \mathrm{ESRF}$ pucks for SPINE standard pins and vials (Cipriani et al., 2006), providing a total capacity of 160 samples. A six-axis (STÄUBLI, Pfäffikon, Switzerland) robot is mounted overhead above the storage dewar providing simple access to the samples and reducing the footprint of the system. The crystal gripping mechanism consists of two pneumatic cryogenic tongs mounted at an angle of $45^{\circ}$ on carbon rods holding the sample (the cap and the LN2-filled vial). A mounting/dismounting/mounting-next-sample cycle can be performed in less than $60 \mathrm{~s}$. The entire robot arm and the cryo-dewar are installed in a safety enclosure which also serves to maintain a low-humidity atmosphere (dew point < $-25^{\circ} \mathrm{C}$ ) minimizing ice formation in the storage dewar. On the diffractometer, the crystals are kept at cryogenic temperatures during data collection by an 800 series Cryostream open flow cryogenic gas cooler (Oxford Cryosystems, Oxford, UK).

\subsection{Detector and detector table}

The standard detector on $\mathrm{P} 13$ is a PILATUS 6M-F (DECTRIS AG, Baden, Switzerland), with $450 \mu \mathrm{m}$ sensor thickness and custom calibration tables for low energies (Julien et al., 2011; Marchal \& Wagner, 2011). The detector translation stage (in-house design) offers five degrees of freedom (vertical and horizontal translation, roll, pitch and yaw) (Fig. 4a) to ensure detector centring on the direct beam upon the change in the incident beam inclination (after adjustments of the KB mirrors), a large vertical $2 \Theta$ offset (up to $25^{\circ}$ ) and a crystal-to-detector distance adjustable between $135 \mathrm{~mm}$ and $1.5 \mathrm{~m}$.

\subsection{Instrument control}

The control of monochromator, mirrors, robotic sample changer and minor components is carried out by master units containing electronics modules for devices such as motors, encoders and intensity monitors (Ristau et al., 2014). The modules are interconnected through a real-time Ethernetbased field bus (EtherCAT, Beckhoff ${ }^{(m)}$, Verl, Germany) (Pazos et al., 2008), which allows for simple and fast synchronization of processes inside an individual instrument and between different instruments. The control PCs are compact and are mounted inside the optical and experimental hutches in small units next to the respective beamline components (Fig. S6), thereby reducing cable length and consequently improving the electromagnetic compatibility.

Most of the low-level instrument control (motion control, analogue and digital $\mathrm{I} / \mathrm{O}$ signal processing, cryogenic and 
vacuum control system, instrument and personnel safety with exception of the radiation safety interlock system provided by DESY) is implemented in programmable logic controllers (PLC) running on embedded PCs that are part of the master units. Low- and high-level control layers are connected by the TINE control system developed by DESY (Bacher, 2007). Instrument functionalities can be accessed through TINE servers from different clients for beamline staff and for user operation.

\subsection{Data acquisition and analysis}

The data acquisition software at $\mathrm{P} 13$ is $M x C u B E$ (Gabadinho et al., 2010), developed at ESRF (Grenoble, France), and adapted to the environment of the PETRA III MX beamlines. It supports standard crystallographic data collection protocols, fluorescence scan acquisition and sample changer operation. Logging into $M x C u B E$ activates the electronic data collection notebook services provided within ISPyB (Delagenière et al., 2011).

Data management foresees simultaneous storing of two copies of collected data on the PPU on a secondary storage system consisting of two network storage servers (DELL, Frankfurt, Germany) with a total capacity of $300 \mathrm{~TB}$ shared between beamlines P12, P13 and $\mathrm{P} 14$. The interconnection between storage servers is provided by InfiniBand high-speed data transfer lines. Data transport to external disks is possible via USB3 ports.

Data processing is performed with a parallelized version of $X D S$ (Kabsch, 2010) running on a 40-core Pilatus Processing Unit (PPU) XL (DECTRIS AG, Baden, Switzerland). Standard crystallographic software including CCP4 (Winn et al., 2011), PHENIX (Adams et al., 2010), SHELX (Sheldrick, 2008) and HKL2MAP (Pape \& Schneider, 2004) is available on dedicated graphics and compute servers for structure solution.

\subsection{Control hutches and user laboratory}

The experimental hutch is directly accessible from the control area, which offers a laboratory bench for small-scale

Figure 4

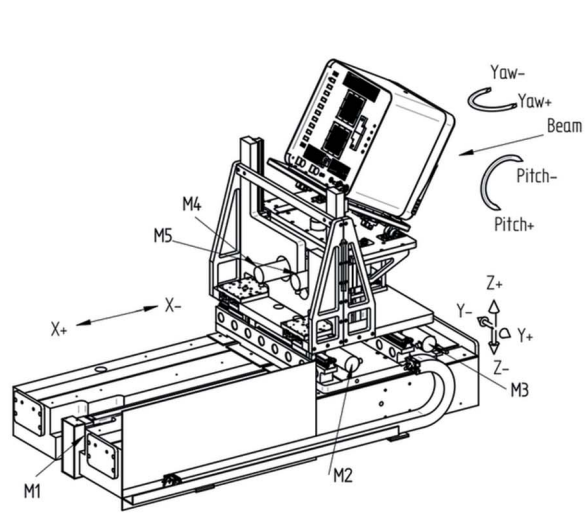

(a)

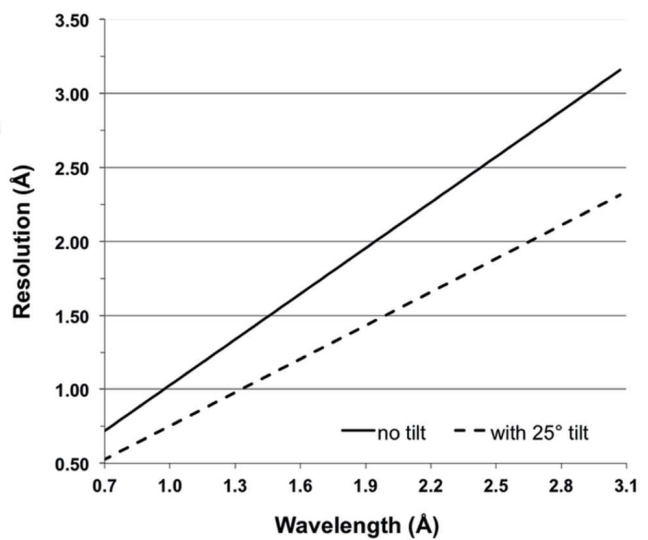

(b)

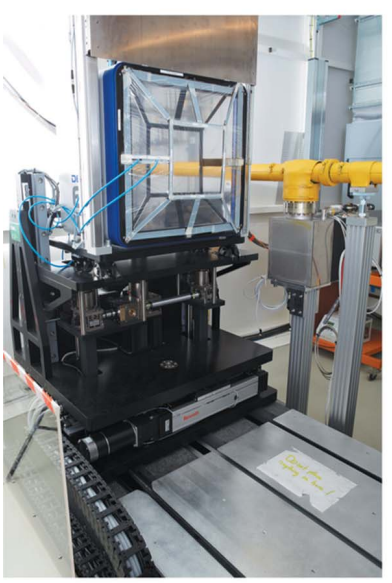

(c)

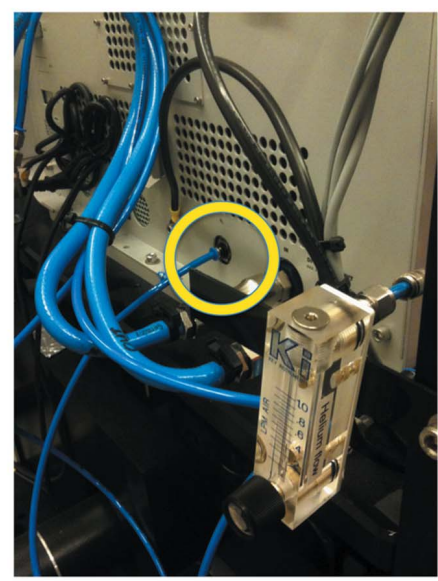

(d)

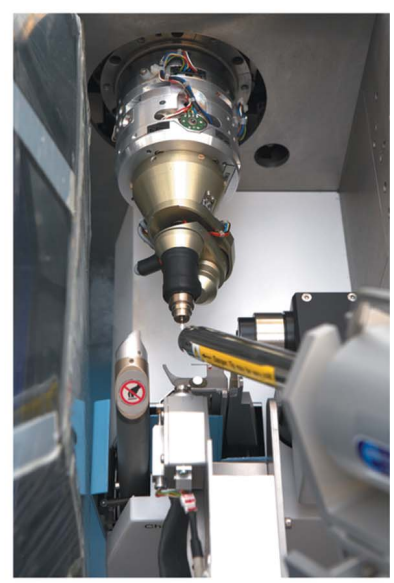

$(e)$

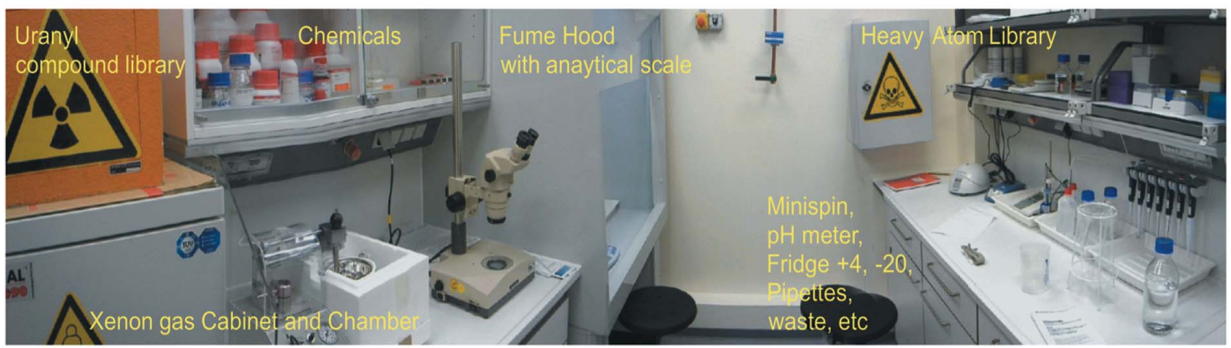

(f)

P13 ancillary facilities. (a) Drawing of the detector table with vertical $2 \Theta$-arm. (b) Diffraction resolution versus energy at the edge of the PILATUS $6 \mathrm{M}-\mathrm{F}$ at $2 \Theta=0^{\circ}$ (full line) and at $2 \Theta=25^{\circ}$ (dashed line). (c) PILATUS 6M-F equipped with the helium cone assembly. ( $d$ ) Back panel of the DECTRIS PILATUS 6M-F with the standard $\mathrm{N}_{2}$ gas inlet highlighted, used also to vent the complete detector with helium gas. (e) Detail of the sample position with helium cone assembly on; the postsample air gap is reduced to $30 \mathrm{~mm}$ at the closest sample-to-detector distance of $135 \mathrm{~mm}$. $(f)$ EMBL sample air gap is reduced to $30 \mathrm{~mm}$ at the closest sample-to-detector distance
derivative laboratory (DLab) located about $15 \mathrm{~m}$ away from the beamline. sample preparation, fast data processing, computing for structure solution and refinement, and data back-up. An additional room for data processing and back-up is available in the vicinity of the beamline. For larger-scale sample preparation, a separate user laboratory is available.

\section{Ancillary facilities}

\subsection{Data collection at energies below $6 \mathrm{keV}$}

A number of measures have been introduced to facilitate the collection of anomalous diffraction data at energies below 
$6 \mathrm{keV}$. Low scattering background and high photon flux is achieved by an all invacuum design all the way to a distance of $50 \mathrm{~mm}$ from the sample. The total thickness of the two diamond windows present in the beamline is $120 \mu \mathrm{m}$ resulting in a transmission of about 20 $25 \%$ at $4 \mathrm{keV}$. Higher harmonics are effectively removed by the doublebounce horizontal deflecting mirrors with bare silica, which have a theoretical transmission of $10^{-3}$ at $12 \mathrm{keV}$ where the highest contribution of the thirdharmonic is present (Fig. 1e). Potential beam hardening effects, arising from the CVD windows, are therefore strongly reduced. It should be noted that the KB mirrors also comprise bare silica and Rh-coated stripes; however, experience has shown that the use of the silica stripe is not required for further harmonic rejection. A scatter guard and a metal capillary are placed immediately upstream of the sample position (Fig. S5) to minimize the in-air background around the sample.

The PILATUS 6M-F custom calibration tables for low energies (Julien et al., 2011; Marchal \& Wagner, 2011) enable accurate and low-noise diffraction data collection in the softer X-ray regime.

For 4-6 keV data collections, a custom-made helium cone (fully compatible with the $2 \Theta$-angle detector stage) is fitted to the detector. The assembly of the helium cone and the housing of the PILATUS detector are flushed with a constant helium flow (Figs. $4 c, 4 d$ ). For the closest crystal-to-detector distance $(135 \mathrm{~mm})$, the helium cone allows to keep $105 \mathrm{~mm}$ of the direct X-ray path from the sample to the detector surface in helium atmosphere. In this configuration, the sample can still be kept at $100 \mathrm{~K}$ using the standard nitrogen cryostream (Fig. 4e) and operation of the MARVIN sample changer is not affected. Equally, the use of the mini- $\kappa$ goniostat is possible for $\Omega$ angular ranges between 0 and $180^{\circ}$ with the helium cone mounted.

The overall endogenous background of $\mathrm{P} 13$ at $4.5 \mathrm{keV}$ X-ray energy was measured by inspection of diffraction images of a lysozyme crystal (Fig. 5) collected with the helium cone in place. The background surrounding the Bragg spots reduces from an average of $1.7 \pm 0.1$ photons pixel $^{-1}$ $\mathrm{s}^{-1}$ at low diffraction angles to $0.13 \pm 0.03$ photons pixel $^{-1}$ $\mathrm{s}^{-1}$ counts pixel ${ }^{-1}$ at high diffraction angles. Exposing the crystal and the mount through their longest dimension marginally alters the background to $1.5 \pm 0.1$ photons pixel $^{-1}$ $\mathrm{s}^{-1}$ at low angles and to $0.19 \pm 0.04$ photons pixel ${ }^{-1} \mathrm{~s}^{-1}$ at high angles.

\subsection{Derivatization laboratory}

A dedicated laboratory 'DLab' for handling of heavy atoms and for preparation of solutions for protein derivatization (Fig. $4 f$ ) is located in the vicinity of the beamline. Currently, the DLab holds a library of more than 150 compounds containing 44 different elements including lanthanide cage compounds (Pompidor et al., 2010; Talon et al., 2011) and uranyl derivatives (Liu et al., 2001). A xenon chamber (Hampton Research, Aliso Viejo, USA) allows preparation of xenon and krypton derivatives for phasing with softer X-rays (Olczak et al., 2003).

\section{Facility access}

Access to the EMBL Hamburg beamlines is available to academic research groups, and is prioritized by the Project Evaluation Committee on scientific grounds only. Proposals for beamline access can be submitted to http://smis.emblhamburg.de. Access for industrial users can be accepted under a commercial agreement. Remote data collection is available. 


\section{Highlights}

At the time of writing, P13 has been accredited with more than 100 Protein Data Bank depositions. Highlights from the available publications include the elucidation of the structural basis of the proinflammatory signalling complex mediated by TSLP (Verstraete et al., 2014); the crystal structure of the eukaryotic translation initiation factor eIF5B (399-852) from Saccharomyces cerevisiae (Kuhle \& Ficner, 2014); the structure and thermodynamics of inhibition of Sporosarcina pasteurii urease (Benini et al., 2014); crystallographic structures of an active Spiegelmer, NOX-D20, bound to its physiological targets, mouse C5a and C5a-desArg (Yatime et al., 2015). Full MAD and Se-SAD capability are implemented as shown by the crystal structure of Geobacillus thermoglucosidasius GH family 52 xylosidase (Espina et al., 2014) solved with Se-SAD data, or by the in-house structure solution of glucose isomerase with a fluorescence scan around the $\mathrm{Pb}$ $L_{\text {III }}$ edge at $13050 \mathrm{eV}$ (data not shown).

With respect to ultra-high-resolution data collection, the crystal structure of the sunflower trypsin inhibitor 1 (SFTI-1) (Karna et al., 2015) and the structures of open and closed states of Candida antarctica lipase B (Stauch et al., 2015) were determined at $0.91 \AA$ resolution using X-rays at $\lambda=1.00 \AA$ $(12.4 \mathrm{keV})$ and $\lambda=0.826 \AA(15.0 \mathrm{keV})$, respectively.

The close interaction of the beamline with the facility for the characterization, preparation and crystallization of samples (SPC) (Boivin et al., 2016) facilitated the determination of the crystal structure and function of the first desulfinase with an acyl-CoA dehydrogenase fold (Schürmann et al., 2015) and of the levansucrase from Erwinia amylovora (Wuerges et $a l ., 2015)$, the structural elucidation of the bispecificity of A domains as a basis for activating non-natural amino acids (Kaljunen et al., 2015), and the structural elucidation of 1,4 benzoquinone inhibition of Sporosarcina pasteurii urease (Mazzei et al., 2016).

\subsection{Cdc $23^{\text {Nterm }}$}

The crystal structure determination of $\mathrm{Cdc} 23^{\mathrm{Nterm}}$, a subunit of the multimeric anaphase-promoting complex (APC) (Cianci et al., 2016), was solved by sulfur SAD phasing at $\lambda=$ $2.69 \AA(4.6 \mathrm{keV})$. At this wavelength, the crystal form of $\mathrm{Cdc} 23^{\text {Nterm }}$ studied, containing two molecules of 282 amino acid residues including six cysteines and five methionines in the asymmetric unit $(65.4 \mathrm{kDa}, 12$ cysteines and 10 methionines in total), has an expected Bijvoet ratio $\left\langle\left|F_{\text {anom }}\right|\right\rangle /\langle F\rangle$ of $2.2 \%$ [compared with $0.8 \%$ at $\lambda=1.54 \AA(8.0 \mathrm{keV})]$. Selectively illuminating two separate portions of the same crystal with an X-ray beam of $50 \mu \mathrm{m}$ diameter allowed macroscopic crystal twinning to be overcome. The initial experimental phases determined by S-SAD allowed automatic tracing of the dimer at $3.1 \AA$ resolution. Subsequent refinement resulted in a model with $R_{\text {factor }}=18.7 \%$ and $R_{\text {free }}=25.9 \%$. Increasing the Bijvoet ratio reduced the demands in terms of multiplicity and in crystal supply required to achieve successful phasing. This was of particular importance as only one crystal of high quality was found.

\subsection{S-SAD phasing of $\mathbf{Z n}$-free insulin at $4 \mathrm{keV}$}

To demonstrate the feasibility of anomalous data collection at an energy of $4.0 \mathrm{keV}$, data were collected on a crystal of $\mathrm{Zn}$ free insulin (Faust et al., 2008) with a beam defocused to $70 \mu \mathrm{m}$ in diameter using the PILATUS 6M-F detector with the helium cone installed. Two $360^{\circ}$ rotation data sets were collected with the $2 \Theta$ arm set to $0^{\circ}$ and $25^{\circ}$, respectively. A third $360^{\circ}$ dataset was collected at an energy of $13.0 \mathrm{keV}$ for phase extension to high resolution (Table S3). For both lowenergy data sets, the anomalous signal-to-noise indicates that anomalous differences of high quality were measured despite the lower multiplicity of the data set collected with the $2 \Theta$ offset (Fig. 6).

In terms of phasing the structure, the number of residues traced by SHELXE (Sheldrick, 2008) in the first electron density obtained by $S H E L X E, N_{\text {traced }}$, was used as a metric. The respective electron density was derived by combining the unrefined solved substructure, the anomalous differences extracted by SHELXC, and 20 cycles of density modification against the $1.4 \AA$ data collected at $13.0 \mathrm{keV}$. While the structure could actually be solved using any of the two low-energy

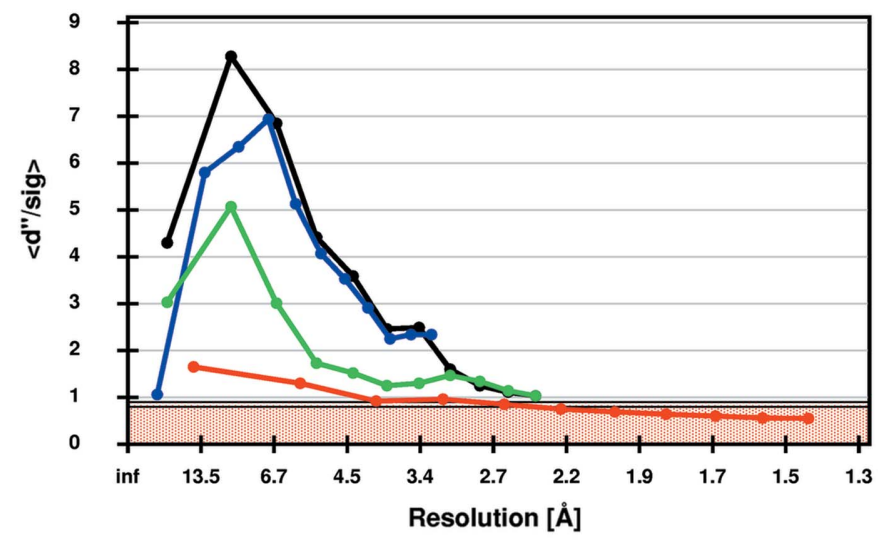

(a)

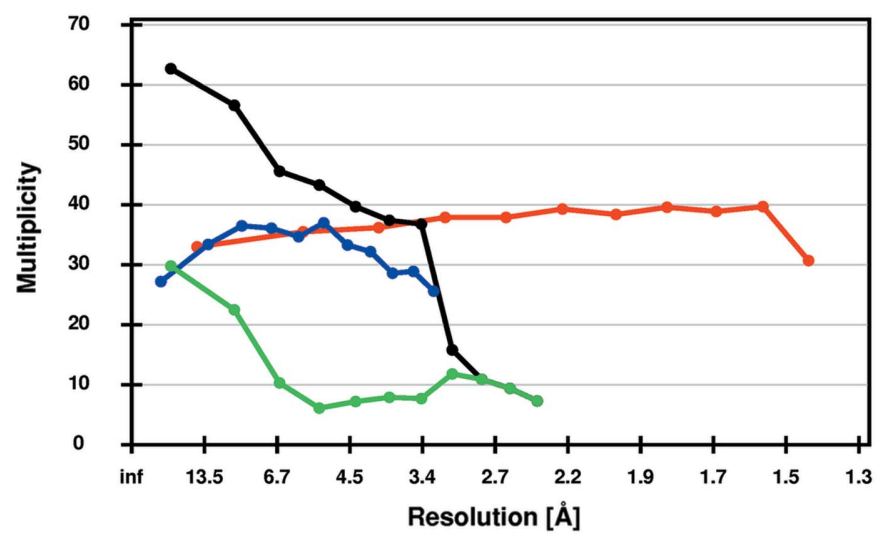

Figure 6

(b)

Data quality statistics for crystals of $\mathrm{Zn}$-free insulin as calculated by SHELXC. (a) Anomalous signal-to-noise $d^{\prime \prime} / \mathrm{sig}$ as a function of resolution. Statistics for data collected at $13 \mathrm{keV}$ are shown in red, for data collected at $4 \mathrm{keV}$ without and with $2 \Theta$-offset in blue and green, respectively, for the combination of the two $4 \mathrm{keV}$ data sets in black. (b) Multiplicity as a function of resolution. Colour codes are the same as in panel $(a)$. 
datasets by themselves or in combination, the data collected at $4 \mathrm{keV}$ with the $2 \Theta$ offset $\left(N_{\text {traced }}=45\right)$ are more useful for phasing than the data collected to a geometrically limited resolution of $3.14 \AA$ at $2 \Theta=0^{\circ}\left(N_{\text {traced }}=26\right)$. The best result was obtained by using a combination of the two data sets collected at $4 \mathrm{keV}\left(N_{\text {traced }}=49\right)$ indicating that the data sets collected at different $2 \Theta$-settings are compatible.

\section{Discussion and conclusions}

P13 translates the high brilliance of the radiation of PETRA III into a small tunable beam with low divergence at the sample position. The beam can be used for high-resolution data collection on crystals with large unit-cell dimensions, phasing applications exploiting X-ray energies between 4 and $17.5 \mathrm{keV}$, and high-resolution data collection at high energies. With the instruments in place, it should be possible to resolve diffraction from crystals with unit-cell parameters of $1000 \AA$ to a resolution of $3.0 \AA$ resolution (assuming the PILATUS $6 \mathrm{M}$ detector to be placed at a distance of $700 \mathrm{~mm}$ from the sample and a spot separation of 4 pixels). Based on the high photon flux and the high detector frame rates, typical data collection times for cryogenically cooled crystals are of the order of a few minutes. In addition to the capabilities geared towards challenging crystallographic applications, the possibility of using relatively large tunable beams with dimensions up to $150 \mu \mathrm{m}$ with high flux in combination with automatic mounting and remote access allows for applications in high-throughput crystal screening and/or high-throughput data collection.

The beam size can be tailored to the size of the crystal by adjusting the curvature of the bimorph KB mirrors, an operation that can be performed within a few minutes with excellent reproducibility, and by introducing apertures of different diameters into the beam. Low-energy $(<6 \mathrm{keV})$ data collections are possible and yield excellent phases as shown by structure determination of $\mathrm{Cdc} 23^{\mathrm{Nterm}}$ (Cianci et al., 2016). With the use of a helium cone, the immediate vicinity of the sample remains accessible as to facilitate standard use of the mini- $\kappa$ goniostat and of the robotic sample mounter.

Overall, the combination of the adjustable focal properties and robust wide-range energy-tunability of the beamline allow optimal conditions to be chosen for both native and anomalous data collections on a wide range of crystals.

\section{Related literature}

The following references are mentioned in the supporting information: Sanishvili et al. (2008); Wikoff et al. (2000).

\section{Acknowledgements}

The authors would like to thank the authors of the PETRA III Technical Design Report (Balewski et al., 2004) for paving the way towards the construction of PETRA III and the construction of the first set of beamlines including P13 and P14. We are grateful to the members of the Scientific Advisory
Board of the EMBL@PETRA3 project, chaired by Dr E. Duke (Diamond Light Source, Ltd, Didcot, UK), for their continuous support and advice. All members of the EMBL Hamburg Instrumentation group are thanked for their dedication to the project. A. Gobbo (EMBL, Grenoble, France) and J. Sinoir (EMBL, Grenoble, France) are thanked for support with the MD2 control software. The MxCuBE consortium is thanked for the enabling and supporting the use of the $M x C u B E$ user interface. Dr R. Signorato (CINEL, Italy) and Dr F. Siewert (BESSY, Germany) are thanked for excellent support during mirror commissioning and metrology. We would like to thank Dr H. Schulte-Schrepping and Dr M. Hesse, Dr M. Tischer and the undulator group FS-US, and Dr J. Spengler and the general infrastructure group FS-TI (DESY, Germany) for excellent cooperation. We acknowledge discussion and advice during the planning of the beamline from Dr H. Franz (DESY, Germany) and Professor E. Weckert (DESY, Germany). We would like to thank many 'friendly' and regular users, in particular Dr Piotr Neumann (Georg-August-Universität Göttingen, Germany), for the continuous feedback and support. P13 was funded by the German Federal Ministry for Education and Research (BMBF, grant number DE/BMBF/05/ES7YE1 'Synchrotronstrahlführungen für strukturbiologische Forschung am PETRA III Speicherring') and by EMBL.

\section{References}

Adams, P. D., Afonine, P. V., Bunkóczi, G., Chen, V. B., Davis, I. W., Echols, N., Headd, J. J., Hung, L.-W., Kapral, G. J., GrosseKunstleve, R. W., McCoy, A. J., Moriarty, N. W., Oeffner, R., Read, R. J., Richardson, D. C., Richardson, J. S., Terwilliger, T. C. \& Zwart, P. H. (2010). Acta Cryst. D66, 213-221.

Arvai, A. (2015). The ADXV User Manual, http://www.scripps.edu/ tainer/arvai/adxv/adxv_1.9.10/AdxvUserManual_v1.1.pdf.

Bacher, R. (2007). Proceedings of the International Conference on Accelerator and Large Experimental Physics Control Systems (ICALEPS07), 15-19 October 2007, Knoxville, TN, USA, p. 217. TPPB27.

Balewski, K., Brefeld, W., Decking, W., Franz, H., Röhlsberger, R. \& Wicker, E. (2004). PETRA III Technical Design Report. DESY, Hamburg, Germany.

Barthelmess, M., English, U., Pflüger, J., Schöps, A., Skupin, J. \& Tischer, M. (2008). Proceedings of the 11th European Particle Accelerator Conference (EPAC'08), 23-27 June 2008, Genoa, Italy, p. 2320

Benini, S., Cianci, M., Mazzei, L. \& Ciurli, S. (2014). J. Biol. Inorg. Chem. 19, 1243-1261.

Boivin, S., Kozak, S., Rasmussen, G., Nemtanu, I. M., Vieira, V. \& Meijers, R. (2016). Methods, 95, 70-77.

Cianci, M., Groves, M. R., Barford, D. \& Schneider, T. R. (2016). Acta Cryst. D72, 403-412.

Cipriani, F., Felisaz, F., Launer, L., Aksoy, J.-S., Caserotto, H., Cusack, S., Dallery, M., di-Chiaro, F., Guijarro, M., Huet, J., Larsen, S., Lentini, M., McCarthy, J., McSweeney, S., Ravelli, R., Renier, M., Taffut, C., Thompson, A., Leonard, G. A. \& Walsh, M. A. (2006). Acta Cryst. D62, 1251-1259.

Cipriani, F., Felisaz, F., Lavault, B., Brockhauser, S., Ravelli, R., Launer, L., Leonard, G. \& Renier, M. (2007). AIP Conf. Proc. 879, 1928-1931. 
Delagenière, S., Brenchereau, P., Launer, L., Ashton, A. W., Leal, R., Veyrier, S., Gabadinho, J., Gordon, E. J., Jones, S. D., Levik, K. E., McSweeney, S. M., Monaco, S., Nanao, M., Spruce, D., Svensson, O., Walsh, M. A. \& Leonard, G. A. (2011). Bioinformatics, 27, 31863192.

Espina, G., Eley, K., Pompidor, G., Schneider, T. R., Crennell, S. J. \& Danson, M. J. (2014). Acta Cryst. D70, 1366-1374.

Faust, A., Panjikar, S., Mueller, U., Parthasarathy, V., Schmidt, A., Lamzin, V. S. \& Weiss, M. S. (2008). J. Appl. Cryst. 41, 1161-1172.

Fischetti, R. F., Stepanov, S., Xu, S., Makarov, O., Urakhchin, A., Sanishvili, R., Smith, W. W., Yoder, D., Benn, R., Corcoran, S., Devarapalli, S., Diete, W., Schwoerer-Boehing, M., Signorato, R., Berman, L. E. \& Smith, J. L. (2005). Acta Cryst. A61, C139.

Fischetti, R. F., Xu, S., Yoder, D. W., Becker, M., Nagarajan, V., Sanishvili, R., Hilgart, M. C., Stepanov, S., Makarov, O. \& Smith, J. L. (2009). J. Synchrotron Rad. 16, 217-225.

Fischetti, R. F., Yoder, D. W., Xu, S., Stepanov, S., Makarov, O., Benn, R., Corcoran, S., Diete, W., Schwoerer-Boehing, M., Signorato, R., Schroeder, L., Berman, L., Viccaro, P. J. \& Smitha, J. L. (2007). AIP Conf. Proc. 879, 754-757.

Flot, D., Mairs, T., Giraud, T., Guijarro, M., Lesourd, M., Rey, V., van Brussel, D., Morawe, C., Borel, C., Hignette, O., Chavanne, J., Nurizzo, D., McSweeney, S. \& Mitchell, E. (2010). J. Synchrotron Rad. 17, 107-118.

Franz, H., Leupold, O., Röhlsberger, R., Roth, S. V., Seeck, O. H., Spengler, J., Strempfer, J., Tischer, M., Viefhaus, J., Weckert, E. \& Wroblewski, T. (2007). Synchrotron Radiat. News, 19, 25-29.

Gabadinho, J., Beteva, A., Guijarro, M., Rey-Bakaikoa, V., Spruce, D., Bowler, M. W., Brockhauser, S., Flot, D., Gordon, E. J., Hall, D. R., Lavault, B., McCarthy, A. A., McCarthy, J., Mitchell, E., Monaco, S., Mueller-Dieckmann, C., Nurizzo, D., Ravelli, R. B. G., Thibault, X., Walsh, M. A., Leonard, G. A. \& McSweeney, S. M. (2010). J. Synchrotron Rad. 17, 700-707.

Julien, M., Benjamin, L., Catalin, U., Vitaliy, M. \& Armin, W. (2011). J. Instrum. 6, C11033.

Kabsch, W. (2010). Acta Cryst. D66, 125-132.

Kaljunen, H., Schiefelbein, S. H., Stummer, D., Kozak, S., Meijers, R., Christiansen, G. \& Rentmeister, A. (2015). Angew. Chem. Int. Ed. 54, 8833-8836.

Karna, N., Łęgowska, A., Malicki, S., Dębowski, D., Golik, P., Gitlin, A., Grudnik, P., Wladyka, B., Brzozowski, K., Dubin, G. \& Rolka, K. (2015). ChemBioChem, 16, 2036-2045.

Kuhle, B. \& Ficner, R. (2014). EMBO J. 33, 1177-1191.

Liebschner, D., Yamada, Y., Matsugaki, N., Senda, M. \& Senda, T. (2016). Acta Cryst. D72, 728-741.

Liu, Y., Ogata, C. M. \& Hendrickson, W. A. (2001). Proc. Natl Acad. Sci. USA, 98, 10648-10653.

Marchal, J. \& Wagner, A. (2011). Nucl. Instrum. Methods Phys. Res. $A, \mathbf{6 3 3}, \mathrm{S} 121-\mathrm{S} 124$.

Mazzei, L., Cianci, M., Musiani, F. \& Ciurli, S. (2016). Dalton Trans. 45, 5455-5459.
Olczak, A., Cianci, M., Hao, Q., Rizkallah, P. J., Raftery, J. \& Helliwell, J. R. (2003). Acta Cryst. A59, 327-334.

Pape, T. \& Schneider, T. R. (2004). J. Appl. Cryst. 37, 843-844.

Pazos, A., Ristau, U. \& Fiedler, S. (2008). Procedings of the 7th International Workshop on Personal Computers and Particle Accelerator Controls (PCaPAC08), 20-23 October 2008, Ljubljana, Slovenia.

Pompidor, G., Maury, O., Vicat, J. \& Kahn, R. (2010). Acta Cryst. D66, 762-769.

Ristau, U., Kolozhvari, A. \& Fiedler, S. (2014). Procedings of the 10th International Workshop on Personal Computers and Particle Accelerator Controls (PCaPAC2014), 14-17 October 2014, Karlsruhe, Germany.

Sanctis, D. de, Beteva, A., Caserotto, H., Dobias, F., Gabadinho, J., Giraud, T., Gobbo, A., Guijarro, M., Lentini, M., Lavault, B., Mairs, T., McSweeney, S., Petitdemange, S., Rey-Bakaikoa, V., Surr, J., Theveneau, P., Leonard, G. A. \& Mueller-Dieckmann, C. (2012). J. Synchrotron Rad. 19, 455-461.

Sanishvili, R., Nagarajan, V., Yoder, D., Becker, M., Xu, S., Corcoran, S., Akey, D. L., Smith, J. L. \& Fischetti, R. F. (2008). Acta Cryst. D64, 425-435.

Schulte-Schrepping, H., Degenhardt, M., Peters, H.-B., Hahn, U., Heuer, J. \& Hesse, M. (2013). J. Phys. Conf. Ser. 425, 042005.

Schürmann, M., Meijers, R., Schneider, T. R., Steinbüchel, A. \& Cianci, M. (2015). Acta Cryst. D71, 1360-1372.

Sheldrick, G. M. (2008). Acta Cryst. A64, 112-122.

Siewert, F., Buchheim, J., Höft, T., Fiedler, S., Bourenkov, G., Cianci, M. \& Signorato, R. (2012). Meas. Sci. Technol. 23, 074015.

Signorato, R., Hignette, O. \& Goulon, J. (1998). J. Synchrotron Rad. 5, 797-800.

Stauch, B., Fisher, S. J. \& Cianci, M. (2015). J. Lipid Res. 56, 23482358.

Talon, R., Kahn, R., Durá, M. A., Maury, O., Vellieux, F. M. D., Franzetti, B. \& Girard, E. (2011). J. Synchrotron Rad. 18, 74 78.

Verstraete, K., van Schie, L., Vyncke, L., Bloch, Y., Tavernier, J., Pauwels, E., Peelman, F. \& Savvides, S. N. (2014). Nat. Struct. Mol. Biol. 21, 375-382.

Wagner, A., Duman, R., Henderson, K. \& Mykhaylyk, V. (2016). Acta Cryst. D72, 430-439.

Wikoff, W. R., Schildkamp, W. \& Johnson, J. E. (2000). Acta Cryst. D56, 890-893.

Winn, M. D., Ballard, C. C., Cowtan, K. D., Dodson, E. J., Emsley, P., Evans, P. R., Keegan, R. M., Krissinel, E. B., Leslie, A. G. W., McCoy, A., McNicholas, S. J., Murshudov, G. N., Pannu, N. S., Potterton, E. A., Powell, H. R., Read, R. J., Vagin, A. \& Wilson, K. S. (2011). Acta Cryst. D67, 235-242.

Wuerges, J., Caputi, L., Cianci, M., Boivin, S., Meijers, R. \& Benini, S. (2015). J. Struct. Biol. 191, 290-298.

Yatime, L., Maasch, C., Hoehlig, K., Klussmann, S., Andersen, G. R. \& Vater, A. (2015). Nat. Commun. 6, 6481. 